\title{
Ahp model for the selection of partner companies in virtual enterprises
}

\author{
Burak Sari • Tayyar Sen • S. Engin Kilic
}

Received: 3 July 2006 / Accepted: 15 May 2007 /Published online: 14 June 2007

(C) Springer-Verlag London Limited 2007

\begin{abstract}
Rising product variety and complexity, shorter time frames to respond, and the continual need to gain new capabilities through innovativeness force the trend of outsourcing to be replaced by strategic alliances, where enterprises or individuals work together towards a common goal and share their responsibilities as well as their profits. Recent developments in information technology have enabled relatively inexpensive, reliable and fast networking to support such alliances in real time. In this context, the virtual enterprise (VE) represents an appropriate cooperation alternative and competitive advantage for the enterprises. $\mathrm{VE}$ is a temporary network of independent companies suppliers, customers, even rivals - linked by information technology (IT) to share skills, costs and access to one another's markets. In this emerging business model of virtual enterprise, the decision support functionality, which addresses issues such as partner company selection, is an important domain to be studied. In this paper, we propose an analytic hierarchy process model to contribute in the selection of the partner companies in the virtual enterprises.
\end{abstract}

B. Sari $(\bowtie)$

School of Management,

Leiden University,

Leiden, Netherlands

e-mail: burak.sari@cetim.org

T. Sen

Industrial Engineering Department,

Middle East Technical University,

Ankara, Turkey

e-mail: tayyar@metu.edu.tr

\section{S. E. Kilic}

Mechanical Engineering Department,

Middle East Technical University,

Ankara, Turkey

e-mail: engink@metu.edu.tr
A case example is also covered to validate the feasibility of the adoption of the model in virtual enterprise situations.

Keywords AHP. Virtual enterprise · Partner selection

\section{Introduction}

Today's dynamic manufacturing environment is characterized by dramatic and often unanticipated changes. In this difficult and challenging milieu, the manufacturing enterprise must develop and implement new and innovative strategies for competitive success. Among the most interesting competitive strategies being explored by manufacturing firms is the concept of the virtual enterprise. The virtual enterprise is a temporary relationship with two or more participants which is formed, operated, and dissolved to accomplish specific short term goals. It differs from existing inter-organizational models by the degree of shared accountability and responsibility of the participants and the structure by which companies contribute their competencies.

We define the VE as a temporary coalition of independent companies that come together to share resources, costs and skills in order to achieve specific business goals that they could not undertake individually within a given time period and at a cost lower than any of the cooperating partners would be able to achieve by themselves [1]. VEs are advantageous owing to their competitive and fast market response in a saturated business environment. VE is meant to establish a dynamic organization through the synergetic combination of dissimilar companies with different core competencies, thereby forming a best of everything consortium to perform a given business project to achieve maximum degree of customer satisfaction [2]. $\mathrm{VE}$ is a temporary consortium of partners from different 
organizations established to fulfill a value adding task, for example fulfilling a product or service demand of a customer.

The VE can also be seen as a closely linked supply chain [3]. As pointed out by Camarinha-Matos and Afsarmanesh [4], a VE is a temporary alliance of enterprises to share skills or core competencies and resources in order to respond to business opportunities, and the cooperation among the enterprises is supported by computer networks. It is vitally important for the companies in a VE to share data and information and to communicate with each other effectively. Thus, in a VE, the companies are connected by computer networks. Therefore, it is crucial to have an information infrastructure so that the data can be managed efficiently and inter-operation can be realized. To achieve this goal, several projects have been done to investigate this problem. Among them are the NIIIP project in the US [5, 6], the PRODNET project [7] and the VEGA project [8] in Europe.

Finding the right partners and establishing necessary conditions for starting the collaboration process might, however, be a costly and time consuming activity and, therefore, an inhibitor of the desired agility. Among others, obstacles include lack of information (e.g., non-availability of catalogs with normalized profiles of organizations) and lack of preparedness of organizations to join the collaborative process. Overcoming the mismatches resulting from the heterogeneity of potential partners (e.g., different as in infrastructures, corporate culture, methods of work, and business practices) requires considerable investment, building trust, a pre-requisite for any effective collaboration, is not straight forward and requires time.

Furthermore, partners' selection is not a simple "optimization" problem. More than a matching process based on potential and abilities (e.g., competencies, capacities, and recommendations), many other factors, some of them of a subjective nature (e.g., personal preferences and established trust based on previous experience), suggest that fully automated processes are not at all a realistic approach. It is rather preferable to conceive the decision support functionality to help the human planner in making decisions.

This paper proposes a decision support system to aid in optimal selection of partner companies for a business initiative in distributed manufacturing environment. This decision support system uses analytic hierarchy process algorithm to provide a quick and optimal selection of partners.

\section{Related research studies}

Some VEs may be long-term alliances that last for an indefinite number of business processes. Other VEs may be established for a single business opportunity, as pointed out by Camarinha-Matos and Afsarmanesh [4]; this is perhaps the most typical kind of VE. The goal of VE is to meet the challenge of customized manufacturing or customer-driven manufacturing. Customer-driven manufacturing will ultimately lead to one of a kind production [3, 9]. Thus, even for a long-term alliance VE, the products manufactured are changed frequently and some partners are changed too. In this way, reconfiguration is done frequently, and this is a great challenge to the VE practice. Therefore, effective techniques for selecting partners in VE practice are essential.

In selecting the partners for a business opportunity in a VE, there are many factors to be taken into consideration. These factors include cost, delivery time, quality, trust, credit, performance and reliability. However, key factors mainly addressed in literature are cost and time. As pointed out by Jagdev and Browne [3], high quality products are a necessary precondition for entry into the market and for many manufacturers high quality is no longer the basis of competitive advantage, so cost and time to market are the basis of competitive advantage. In doing research for the PRODNET project, Camarinha-Matos and Cardoso [10] present a framework for partner selection and describe the functionalities in detail, but no techniques to make the tradeoff based on the cost and time are proposed. Under VE and supply chain management, the partner selection problem is studied by Gunasekaran [11] and Maloni [12], and they point out that the mathematical models and optimization methods are still a challenge. The partner selection problem is also studied under project management in the cooperation relationship of subprojects contracted by partners [13-15]. In the study of Brucker et al. [13], the partner selection is embedded in the project scheduling problem.

In Wang et al.'s [19] study, the costs and completion time of the subprojects bidden by the candidates are taken into consideration and a mathematical programming model is presented to model the problem, and the problem is solved by a genetic algorithm. In a VE environment for manufacturing, the partners are geographically distributed, so besides the cost and time required for performing the tasks by the partners, material transportation between partners consume money and time too. Such cost and time are significant enough not to be ignored. With the transportation cost and time considered, the partner selection problem is much more complicated. Taking the processing cost and the transportation cost into account, $\mathrm{Wu}$ et al. [20] modeled the partner selection problem by a network model and an efficient algorithm was presented to solve it. However, in that model, the time factor is neglected.

Another key construct in the selection of partners is the risk issue related to cooperating with new and unknown or 
less familiar partners. Inclusion of new partners possessing the competencies required in a specific situation is seen by many as one of the major challenges related to virtual enterprises [16]. Risk/uncertainty related to co-operating with new partners (are the partners trustworthy?) in a global environment should also be considered in partner selection process. For example, Petroni [17] concluded that the relative importance assigned to a partner attribute was primarily based on the type of risk involved in a specific purchasing situation.

One of key issues in forming and succeeding the VE is the matter of trust. Trust is also a key requirement in order to make information and knowledge-sharing within these types of strategic alliance work. Partner performance is a trust building element. Purdy [18] suggested that management would generally be willing to pay $4-6 \%$ higher than the lowest acceptable bid if product performance is superior. Based on a comprehensive review of partner evaluation methods, Sarkis et al. [19] concluded that performance was the highest ranked factor, followed by delivery time and cost. It can be concluded from these studies that partner selection decisions must not be exclusively based on least cost, delivery time, risk criteria and that also a critical factor, such as partner past performance need to be incorporated into the evaluation and selection process [17]. Therefore, it is important to have some form of performance management to both evaluate individual participation and contribution as well as to score relative performance against the shared goals.

Several multi-criteria, mathematical programming, and other advanced methodologies have also been proposed for partner selection. Some of these methods are weighted linear models, linear programming, analytic hierarchy process, data envelopment analysis, neural networks, etc. Although several effective techniques and models have been utilized for evaluating partners, there is little work in incorporating variability measures into the evaluation process. Clearly, integration of performance variability into the decision making process, and the identification of effective alternative choices provides the buyer with flexibility in the final selection process. Different from other researchers we propose the task price, caution price (in terms of risk or commitment), task completion probability (representing delivery time) and the partners' performance (as a combination of quality, progress and delivery performances) as the criteria to be considered in the partner selection process. The "quality assurance" performance of the partner is measured in terms of the ratio of the acceptable batch size of the product to the received number of product. Delivery dimension is measured in terms of delivery quantity and delivery delay which affects partner's overall performance, because too less delivery quantity or too late delivery will decrease the productivity. Late or less submission of progress will create distrust between the partner and virtual enterprise. Therefore it is considered as a critical factor in the evaluation of partner performance [24].

Besides, it is quite obvious that there are several commercial products available in the market aiming to aid multi-criteria selection for different applications. However, most of these products are developed as a stand alone application and lack of interoperability with the other modules existing in a specific application. One of the biggest advantages of using proposed AHP model is easy to integrate in VE system and user can customize the selection process through including or excluding any one of four criteria. This flexibility enhances the robustness of model in comparison with other techniques. Other advantages of using AHP, in the partner selection are listed below:

(i) The partner selection by AHP takes into consideration both the quantitative and qualitative factors. It is obvious from the model that some of the qualitative terms as level of commitment and performance are not easy to represent in AHP model. In order to take into account these qualitative factors in model, we have tried to come up with a quantitative value for these factors. Level of commitment or risk of having partner is measured as caution cost which is the cost that the partner must pay to the VE if the partner decides the give up before the assigned task is finished. On the other hand, past performance of a partner is assessed through an ANN model [24] which is based on delivery status of the task (late or early), quality of the completed task (\% acceptable) and progress report submissions (late, early or none).

(ii) AHP can display complicated selection factor in simple concepts of hierarchy, which can be accepted easily by a decision-maker.

(iii) AHP goes through a dynamic group discussion and denotes the priority of a decision with certain numerical values. It does not involve statistics or probability theory, thus giving the user a better sense of reality.

(iv) AHP involves group discussion and dynamic adjustment to finally achieve the consensus. The evaluation is conducted by the participating experts who decide jointly on the parameters for pairwise comparison. It is thus more of a qualitative analysis.

(v) Non-quantified elements, after group evaluation and a mathematical process can be quantified by numerical values to indicate a decision's priority. A decisionmaker can reach the choice of partner in a very short time without resorting to precise data. 


\section{Analytic hiearchy process}

The analytic hierarchy process (AHP) was developed by Thomas Saaty [21] in the early 1970s. The strength of the AHP approach lies in its ability to structure a complex, multiattribute, multiperson and multiperiod problem hierarchically. In addition, it can also handle both qualitative (through representing qualitative attributes in terms of quantitative values) and quantitative attributes. Pairwise comparisons of the elements (usually, alternatives and attributes) can be established using a scale indicating the strength with which one element dominates another with respect to a higher level element. This scaling process can be translated into priority weights (scores) for comparison of alternatives.

The general approach followed in AHP is to decompose the problem and to make pairwise comparisons of all the elements (attributes, alternatives) at a given level with respect to the related elements in the level just above. AHP consists of three stages of problem solving decompositions, comparative judgements and synthesis of priorities. The degree of preference of the decisionmaker in the choice for each pairwise comparison is quantified on a scale of 1 to 9 , and these quantities are placed in a matrix. A preference of 1 indicates equality between two items while a preference of 9 (absolute importance) indicates that one item is 9 times larger or more important than the one to which it is being compared. This scale was originally chosen, because in this way comparisons are being made within a limited range where perception is sensitive enough to make a distinction.

AHP usually involves three stages of problem solving: the principles of decomposition, comparative judgments, and synthesis of priority. The decomposition principle calls for constructing a hierarchy or network to represent a decision problem. The overall objective is located at the top of the hierarchy, and the criteria, sub criteria, and alternatives are placed at each descending level of the hierarchy. To apply the principle of comparative judgment, the users set up a comparison matrix at each level by comparing pairs of criteria, or pairs of alternatives at the lowest level according to Table 1. Once the matrix of pairwise comparisons has been developed, one can estimate the relative priority for each of the alternatives in terms of the specific criteria. Preferences derived from a criteria or sub criteria matrix are used to calculate a composite weight for each alternative. This part of AHP is referred to as synthesis. This enables AHP to obtain not only the rank order of the alternatives, but also their relative standings measured on a ratio scale. The alternative with the highest overall rating is usually chosen as a final solution.
Table 1 Interpretation of entries in a pairwise comparison matrix

\begin{tabular}{ll}
\hline Value of aij & Interpretation \\
\hline 1 & Objectives $\mathrm{i}$ and $\mathrm{j}$ are equal of importance \\
3 & Objective $\mathrm{i}$ is weakly more important than objective $\mathrm{j}$ \\
5 & $\begin{array}{c}\text { Experience and judgement indicate that objective } \mathrm{i} \text { is } \\
\text { strongly more important than objective } \mathrm{j}\end{array}$ \\
7 & $\begin{array}{l}\text { Objective is very strongly or demonstrably more } \\
\text { important objective } \mathrm{j}\end{array}$ \\
9 & $\begin{array}{l}\text { Objective } \mathrm{i} \text { is absolutely more important than objective } \mathrm{j} \\
\text { Intermediate values-for example, a value of } 8 \text { means } \\
\text { that objective } \mathrm{i} \text { is midway between strongly and } \\
\text { absolutely more important than objective } \mathrm{j}\end{array}$
\end{tabular}

\section{AHP for selection of partners in VE}

Partner selection depends upon many factors. The factors identified in this paper include unit price of the task, caution cost, completion probability of the task and past performance of the partner. These factors act as attributes in AHP and partners considered serve as alternatives thus constituting the last level of hierarchy. The decision hierarchy for the partner selection is shown in Fig. 1.

The factors affecting the partner selection are as follows:

(1) Unit cost: Cost is a major factor which influences the partner selection. A partner bid involving higher cost is liable to be rejected on economic ground. The total task quantity also influences the overall price.

(2) Caution cost: Level of commitment is measured in terms of a caution cost which is the cost that the partner must pay to the VE if the partner decides the give up before the assigned task is finished and is secured in the form of letter of credit. Thus, the higher this value is, the more preferable for the VE.

(3) Completion probability: The probability of completing the task by the given time period is calculated using program evaluation review technique (PERT). PERT is a review technique which is developed to schedule the projects and to cover uncertainty of activity time estimates [22]. PERT uses three time estimates for each activity. Basically, this means each activity duration can range from an optimistic time to a pessimistic time, and a weighted average can be computed for each activity. Knowing the weighted average and variances for each task allows the system administrator to compute the probability of meeting prespecified task duration.

(4) Past performance: Overall performance of the partner company which is computed by taking the average of the partner performances shown during each previously executed task. Performance variability is based 
Fig. 1 Decision hierarchy of partner selection

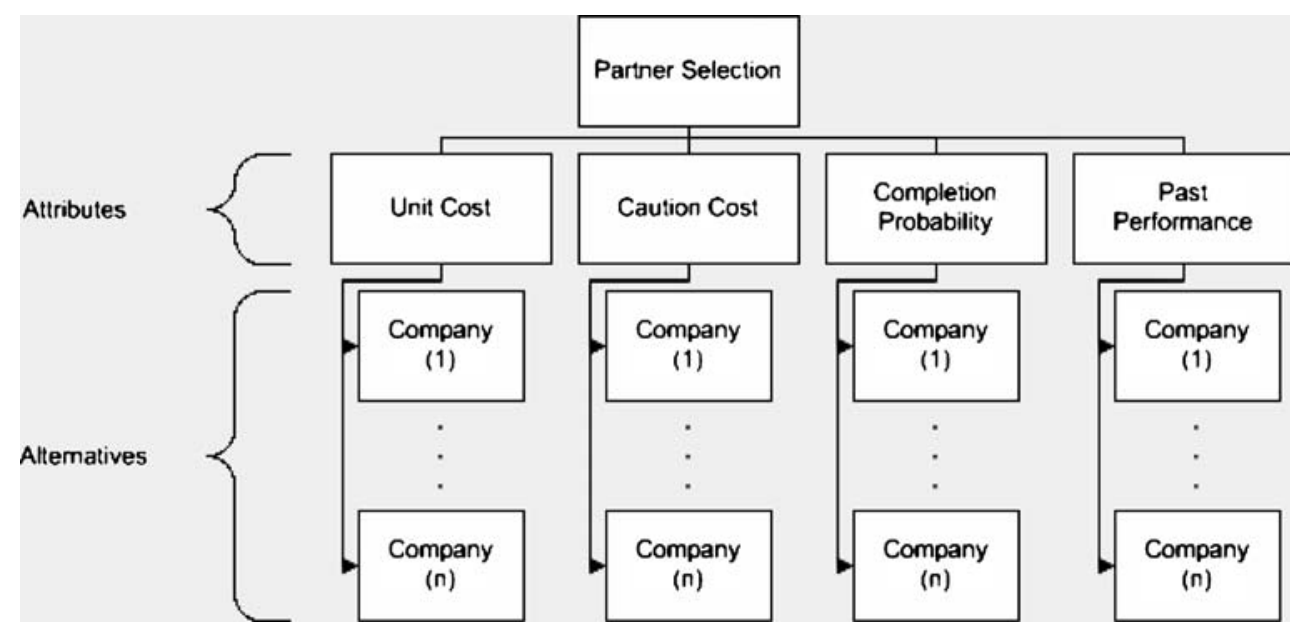

on delivery status of the task (late or early), quality of the completed task ( $\%$ acceptable) and progress report submissions (late, early or none). A neural network model is developed to establish the performance score of each partner [24].

\subsection{Proposed steps of partner selection using AHP}

(i) Define the overall objective.

(ii) Define the structured hierarchy consisting of attributes (criteria for the partner selection for a given product) and alternatives (member companies).

(iii) Determination of the priority weights of the attributes using pairwise comparison matrix and its consistency ratio.

(iv) Determination of priority weights of alternatives with respect to attributes (comparison of various company bids with respect to the individual criteria for selection) and consistency ratio for each pairwise comparison matrix.

(v) Enumeration of overall priority weights for all of the alternatives (companies) and consistency ratio for entire hierarchy.

The partner having the highest priority weight is selected. Various steps of the partner selection process are described in Fig. 2.

\subsection{Case study}

To demonstrate the application of the developed AHP model in a real VE case, a case study entitled as "production of a screwdriver" is presented in this section to illustrate the key activities related to selecting required VE partners. Please note that, only implementation phase of AHP was presented in this paper. For additional information regarding other stages in setting up and operating VE, the reader should be redirected at [23]. Due to confidential issues, company names are hidden and represented by Interested Partner (IP). Interested partner can be defined as a member of network wiling to join a specific VE.

Considering a product specifications coming from customer, VE Initiator is decomposed the product into the four tasks (T1, T2, T3, T4) as shown in Table 2 and looking for the four partners with the relevant skills to execute these tasks.

IP-A, IP-B, IP-C and IP-D are interested partners for the first task of the product (T1; manufacturing of the grip head), and they bid to become a part of the VE. The

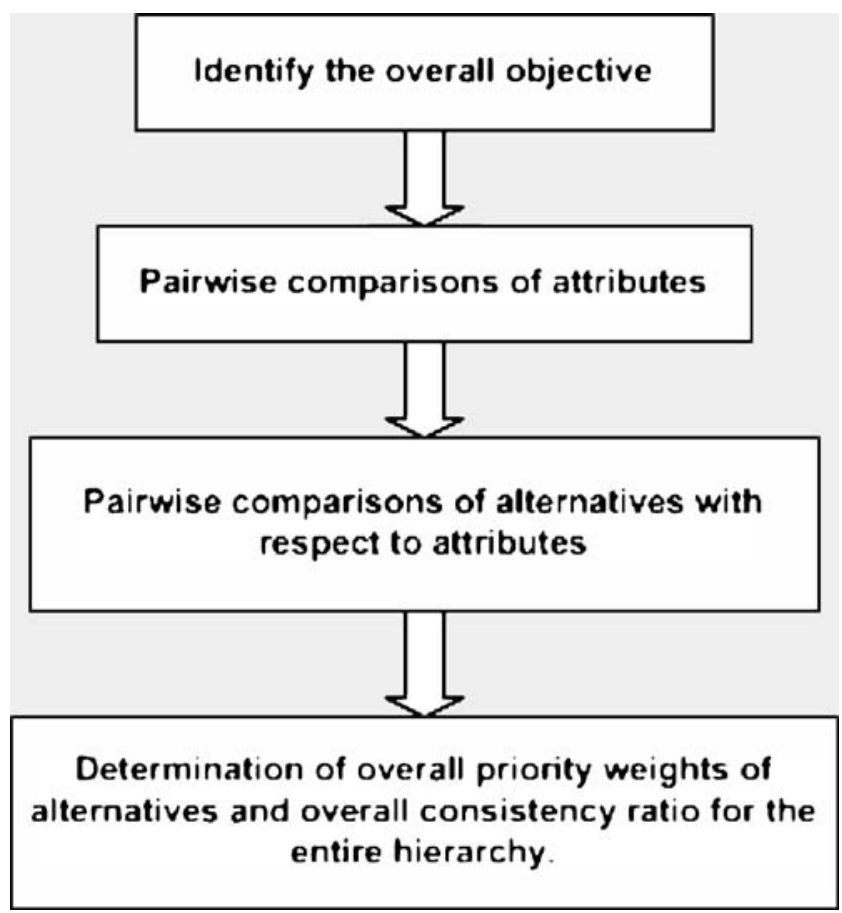

Fig. 2 Overview of the selection process using AHP 
Table 2 Tasks' details

\begin{tabular}{|c|c|c|c|}
\hline Task No. & Task name & Technical specification & Quantity \\
\hline $\mathrm{T} 1$ & $\begin{array}{l}\text { Manufacturing } \\
\text { of the grip } \\
\text { head }\end{array}$ & $\begin{array}{l}\text { Material: free cutting steel, } \\
\text { tolerance (for all } \\
\text { measurements): } 0.1 \mathrm{~mm} \text {, } \\
\text { surface roughness: } 60 \mu \mathrm{m}\end{array}$ & 80 \\
\hline $\mathrm{T} 2$ & $\begin{array}{l}\text { Manufacturing } \\
\text { of the grip }\end{array}$ & $\begin{array}{l}\text { Material: free cutting steel, } \\
\text { tolerance (for all } \\
\text { measurements): } 0.1 \mathrm{~mm} \text {, } \\
\text { surface roughness: } 60 \mu \mathrm{m}\end{array}$ & 80 \\
\hline $\mathrm{T} 3$ & $\begin{array}{l}\text { Manufacturing } \\
\text { of the flat tip }\end{array}$ & $\begin{array}{l}\text { Material: cold work steel, } \\
\text { tolerance (for all } \\
\text { measurements): } 0.1 \mathrm{~mm} \text {, } \\
\text { surface roughness: } 60 \mu \mathrm{m}\end{array}$ & 80 \\
\hline $\mathrm{T} 4$ & $\begin{array}{l}\text { Assembly of } \\
\text { the parts }\end{array}$ & Shrink fit \& honing & 80 \\
\hline
\end{tabular}

objectives and the values for each partner that are considered for the evaluation and the constraints are shown in Table 3. It can be seen that IP-D does not meet the unit cost constraint and will not be considered in the selection process.

Knowing the weighted average duration and variances for the task allows the system to compute the probability of meeting given task duration. The reader should follow the steps described in the hypothetical example given next. (The jargon is difficult for those not familiar with statistics, but the process is relatively simple after working through a couple of examples.)

The weighted average task duration is computed by the following formula:

$T_{e}=\frac{a+4 m+b}{6}$

where

$\mathrm{T}_{e} \quad$ weighted average task duration

$a$ optimistic task duration (1 chance in 100 of completing the task earlier under normal conditions)

Table 3 Bids coming from the IPs

\begin{tabular}{|c|c|c|c|c|c|c|c|c|c|}
\hline \multicolumn{2}{|c|}{$\begin{array}{l}\text { Alternatives objectives } \\
\text { (units, constraints) }\end{array}$} & \multicolumn{2}{|c|}{ IP-A } & \multicolumn{2}{|c|}{ IP-B } & \multicolumn{2}{|c|}{ IP-C } & \multicolumn{2}{|c|}{ IP-D } \\
\hline \multirow{2}{*}{\multicolumn{2}{|c|}{$\begin{array}{l}\text { Unit cost }(\mathrm{YTL},<0.25 \mathrm{YTL}) \\
\text { Caution cost }(\mathrm{YTL},>200 \mathrm{YTL})\end{array}$}} & \multicolumn{2}{|c|}{0.23} & \multicolumn{2}{|c|}{0.21} & \multicolumn{2}{|c|}{0.19} & \multicolumn{2}{|c|}{0.26} \\
\hline & & 21 & & 28 & & 20 & & 215 & \\
\hline \multirow{3}{*}{$\begin{array}{l}\text { Average } \\
\text { duration } \\
(\text { day, }<5)\end{array}$} & $\begin{array}{l}\text { Pessimistic } \\
\text { duration (day,) }\end{array}$ & 5 & 7 & 4 & 5 & 5 & 8 & 4 & 6 \\
\hline & $\begin{array}{l}\text { Most Likely } \\
\text { duration (day,) }\end{array}$ & & 4 & & 3 & & 5 & & 4 \\
\hline & $\begin{array}{l}\text { Optimistic } \\
\text { duration (day,) }\end{array}$ & & 3 & & 2 & & 2 & & 3 \\
\hline
\end{tabular}

$b \quad$ optimistic task duration (1 chance in 100 of completing the task later under normal conditions)

$m$ most likely task duration

When three time estimates have been specified by the interested partners, the above equation can be used to compute the weighted average duration for the related task. The variability in the task duration estimates is approximated by the following equations: Equation 2 represents the standard deviation for the task.

$\sigma_{T_{e}}=\left(\frac{b-a}{6}\right)$

The equation below (Eq. 3) is used to compute the " $Z$ " value found in the statistical tables $(Z=$ number of the standard deviations from the mean), which in turn, tells the probability of completing the task in the time specified.

$Z=\left(\frac{T_{s}-T_{e}}{\sigma_{T_{e}}}\right)$

where

$T_{S}=$ scheduled task duration (given as a constraint)

$T_{e}=$ expected or weighted average task duration

$Z=$ probability (of meeting scheduled duration) found in statistical Table 4

For example, what is the probability of the IP-B to complete the task before the given task duration? Using the formula for the $\mathrm{Z}$ value, one can compute the probability as follows:

$Z=\left(\frac{T_{s}-T_{e}}{\sigma_{t_{e}}}\right)=\left(\frac{5-4}{\left(\frac{5-2}{6}\right)}\right)=\frac{+1}{0.5}=2$

Reading from the Table 4 , a $\mathrm{Z}$ value of +2 gives a probability of 98 which is interpreted to mean there is a $98 \%$ chance of completing the task on or before the 5 days. Applying the same procedure to the other given bids, we have got the completion probabilities of IPs as in Table 5. Besides that, overall performance scores of the IPs are also given in Table 5. Please note that IP, who did not execute any type of task in the virtual enterprise before, will get a performance score of 5 over 10 .

Table 4 Z - Probability

\begin{tabular}{llll}
\hline Z Value & Probability & Z value & Probability \\
\hline-2.0 & 0.02 & +2.0 & 0.98 \\
-1.5 & 0.07 & +1.5 & 0.93 \\
-1.0 & 0.16 & +1.0 & 0.84 \\
-0.7 & 0.24 & +0.7 & 0.76 \\
-0.5 & 0.31 & +0.5 & 0.69 \\
-0.3 & 0.38 & +0.3 & 0.62 \\
-0.1 & 0.36 & +0.1 & 0.54 \\
\hline
\end{tabular}


Table 5 Completion probabilities and performance scores

\begin{tabular}{llll}
\hline Alternatives objectives & IP-A & IP-B & IP-C \\
\hline Completion probability (\%) & 50 & 98 & 50 \\
Overall performance score & 8.3 & 9.22 & 8.7 \\
\hline
\end{tabular}

\subsubsection{Pairwise comparison matrix for the prespecified objectives}

In this research, we have four objectives for the selection of partners. These are unit cost, caution cost, completion probability and overall performance score. We begin writing down an $4 \times 4$ matrix (known as the pairwise comparison matrix). The entry in row $i$ and column $j$ of $A$ (calling it $\mathrm{a}_{\mathrm{ij}}$ ) indicates how much more important objective $i$ is than objective $j$. "Importance" is to be measured on an integer-valued 1-9 scale, with each number having the interpretation shown in Table 1. For all $I$, it is necessary that $a_{i i}=1$. If, for example, $a_{13}=3$, objective 1 is weakly more important than objective 3 . If $a_{i j}=k$, then for consistency, it is necessary that $a_{j i}=1 / k$. Thus if $\mathrm{a}_{13}=3$, then $\mathrm{a}_{31}=1 / 3$ must hold.

We have identified the following pairwise comparison matrix of our four objectives for the demanded product $(\mathrm{CC}=$ caution cost, $\mathrm{CP}=$ completion probability, $\mathrm{PS}=$ performance score, $\mathrm{UC}=$ unit cost):

$$
\begin{aligned}
& C P \\
& {\left[\begin{array}{cccc}
1 & C P & P S & U C \\
3 & \frac{1}{3} & 2 & \frac{1}{6} \\
\frac{1}{2} & \frac{1}{4} & 4 & \frac{1}{2} \\
6 & 2 & 8 & \frac{1}{8} \\
6 & 2 & & 1
\end{array}\right]}
\end{aligned}
$$

Unfortunately, some of the pairwise comparisons are inconsistent. To illustrate the meaning of consistency, note that since $\mathrm{a}_{13}=2$, VE initiator believes $\mathrm{CC}$ is twice as important as PS. Since $\mathrm{a}_{21}=3$, initiator also believes that $\mathrm{CP}$ is 3 times as important as CC. Consistency of preferences would imply that initiator should feel that $\mathrm{CP}$ is $2(3)=6$ times as important as PS. Since $\mathrm{a}_{23}=4$, however, initiator believes that $\mathrm{CP}$ is 4 times as important as P.: This shows that initiator's pairwise comparisons exhibit a slight inconsistency. Slight inconsistencies are common and do not cause serious difficulties.

\subsubsection{Weights}

For the ith objective (in this case, $\mathrm{i}=1,2,3,4$ ), AHP generates (by a method to be described shortly) a weight $\mathrm{w}_{\mathrm{i}}=1(\mathrm{i}=1,2,3,4)$ for the ith objective. For convenience, the chosen weights always sum to 1 . Using pairwise comparison matrix, we have found the weights to be as follows ( $\mathrm{w}_{1}$ for $\mathrm{CC}, \mathrm{w}_{2}$ for $\mathrm{CP}, \mathrm{w}_{3}$ for PS, $\mathrm{w}_{4}$ for $\mathrm{UC}$ ):

$w_{1}=0.1036, w_{2}=0.2776, w_{3}=0.0635, w_{4}=0.5532$

(These weights fail to add up to 1 due to rounding.) The weights also indicate that a unit cost is the most important objective, followed by the completion probability, caution cost, and overall performance of the interested partner. Next we have determined how well each IP "scores" on each objective. Each IP scores on each objective is shown in Table 6.

Using objectives weights and the score of each IP on each objective, we compute the overall score of the jth IP $(\mathrm{j}=1,2,3)$ as follows:

$\sum_{i=1}^{i=4} w_{i} \quad$ (IP j's score on objective i)

Now the initiator should choose the IP with the highest overall score. Note that the overall score gives more weight to an IP's score on the more important objectives. Computing each IP's overall score, we obtain

$$
\begin{aligned}
\text { IP-A overall score }= & 0.1036(0.2114)+0.2776(0.1) \\
& +0.0635(0.1429)+0.5532(0.1638) \\
= & 0.15
\end{aligned}
$$

IP-B overall score $=0.1036(0.6551)+0.2776(0.8)$

$$
\begin{aligned}
& +0.0635(0.4286)+0.5532(0.2972) \\
= & 0.48
\end{aligned}
$$

$\mathrm{IP}-\mathrm{C}$ overall score $=0.1036(0.1335)+0.2776(0.1)$

$$
\begin{aligned}
& +0.0635(0.4286)+0.5532(0.539) \\
= & 0.37
\end{aligned}
$$

Thus, the AHP would indicate that the initiator should assign the first task of the product to the IP-B. The sum of the IP weights should always give 1 .

\subsubsection{Results}

In this case study, a production of a screwdriver is realized with the attendance of various network members which were responsible for the establishment of four diverse tasks in a given time period. In this scope, the product with multi-parts has been decomposed into four tasks and for

Table 6 Score for each IP and objective

\begin{tabular}{llll}
\hline Alternatives objectives & IP-A & IP-B & IP-C \\
\hline Caution cost & 0.2114 & 0.6551 & 0.1335 \\
Completion probability & 0.1 & 0.8 & 0.1 \\
Overall performance score & 0.1429 & 0.4286 & 0.4286 \\
Unit cost & 0.1638 & 0.2972 & 0.539 \\
\hline
\end{tabular}


each task an average of three bids has been given by members, thus 13 bids have been collected in total. A total product price, 178.48YTL for a batch size of 80 has been offered to the customer. Completion probability, the probability of completing the product by a given due date, has been calculated as $\% 100$. Sample statistics related with evaluation of member bids are shown in Fig. 4.

The AHP is by nature a multi-stakeholder and multicriteria approach to decision support, well suited to selecting partners in a distributed VE environment. Within a multi-criteria analysis framework, it can be a powerful decision-support tool. While the attractive features of this approach are evident, some comment about limitations is warranted, and indeed multi-criteria analysis (MCA) and multi-objective decision support systems (MODSS) methods in general have their share of detractors. Some of the advantages and limitations of this approach are listed in Table 7, based on experience in the research reported here.

\subsection{Developed VE system}

An important contribution in developing VE methodology was made in $[1,23]$, which addresses a new rapid response methodology for the formation of VE, to enable SMEs to co-operate in the distributed manufacturing environment that dramatically saves time and reduces product engineering costs. This methodology assists SMEs desiring to enter into a virtual relationship by defining the functions and interfaces of critical business processes, thus allowing for a more rapid and efficient integration of the expertise which will be contributed by each partner in the virtual company. As a part of developed methodology, a comprehensive case study has been done through to validate the implementation of AHP model in a real VE system.

The web-based interface of the VE system is being implemented using the ASP.NET programming model. VB-
Script is used throughout the pages. Visual tools such as buttons, figures, combo- and textboxes are applied for a userfriendly interface. The screen shots of the web pages (captured from the case study) designed for the determination of the objectives weights and evaluation of the interested partners scores are given in Figs. 3 and 4, respectively.

\section{Conclusion}

Virtual enterprises are of increasing importance mainly due to their flexibility, agility and efficiency. These main characteristics enable VEs to have successful behavior in dynamic and complex business environments. In a global manufacturing environment, companies have to manufacture customized products with low cost and rapid response. This requires that enterprises should have the agility to response to the demands of the market. It is believed that agility can be realized by dynamically reconfigurable virtual enterprise. However, the configuration of virtual enterprises is a challenge to us.

To be competitive, the manufacturing cost, the time to market and performance are the most important factors. In this paper, the analytic hierarchy process is used for the selection of partners in virtual enterprises. This method provides a comprehensive framework for solving the problem of partner selection. It enables the engineer to cope with the intuitive, the rational, and irrational factors, all at the same time. This method can be regarded as a factor weighting approach providing a formal weighting mechanism to achieve a higher level of consistency.

The proposed selection methodology was found suitable not only for the partner selection but also for other application types. In actual application, the future user can devise more hierarchies and consider the problem in greater details.

Table 7 Favourable features and drawbacks of the analytic hierarchy process

\begin{tabular}{|c|c|}
\hline Advantages & Limitations \\
\hline $\begin{array}{l}\text { A systematic approach is provided to identification of stakeholder } \\
\text { objectives and preferences. }\end{array}$ & $\begin{array}{l}\text { Priority rankings are confined to within stakeholder groups, } \\
\text { and little assistance is provided towards dispute resolution. }\end{array}$ \\
\hline $\begin{array}{l}\text { Economic and non-economic (including social and environmental) } \\
\text { objectives and sub-objectives can be taken into account in the } \\
\text { assessment of management options. }\end{array}$ & $\begin{array}{l}\text { There is lack of agreement on how to identify stakeholder groups, } \\
\text { and how to select samples or representatives from them. }\end{array}$ \\
\hline $\begin{array}{l}\text { Quantifiable and non-quantifiable factors can be included } \\
\text { in the analysis. }\end{array}$ & $\begin{array}{l}\text { Problems with inconsistencies in preferences between objectives } \\
\text { sometimes arise. }\end{array}$ \\
\hline $\begin{array}{l}\text { Scientific judgment can be combined with personal opinion } \\
\text { in the evaluation of policy alternatives. }\end{array}$ & $\begin{array}{l}\text { AHP is sometimes thought of as a 'soft' decision-support approach, } \\
\text { which does not tackle the difficult estimation problems. }\end{array}$ \\
\hline $\begin{array}{l}\text { Relatively simple pairwise comparison allows elicitation of } \\
\text { preferences for objectives by stakeholder groups. }\end{array}$ & $\begin{array}{l}\text { The highly subjective nature of preference weights and rapid } \\
\text { elicitation can lead to questions of validity. }\end{array}$ \\
\hline $\begin{array}{l}\text { The desirability of alternative management options can be ranked } \\
\text { for individual stakeholder groups. }\end{array}$ & Unrealistic expectations about policy decisions can be generated. \\
\hline
\end{tabular}


Fig. 3 Determination of the objectives' weights

\section{Objectives' Weights}

Pairwise Comparison Matrix Size: $4 \times 4$

Consistency Status: Consistent

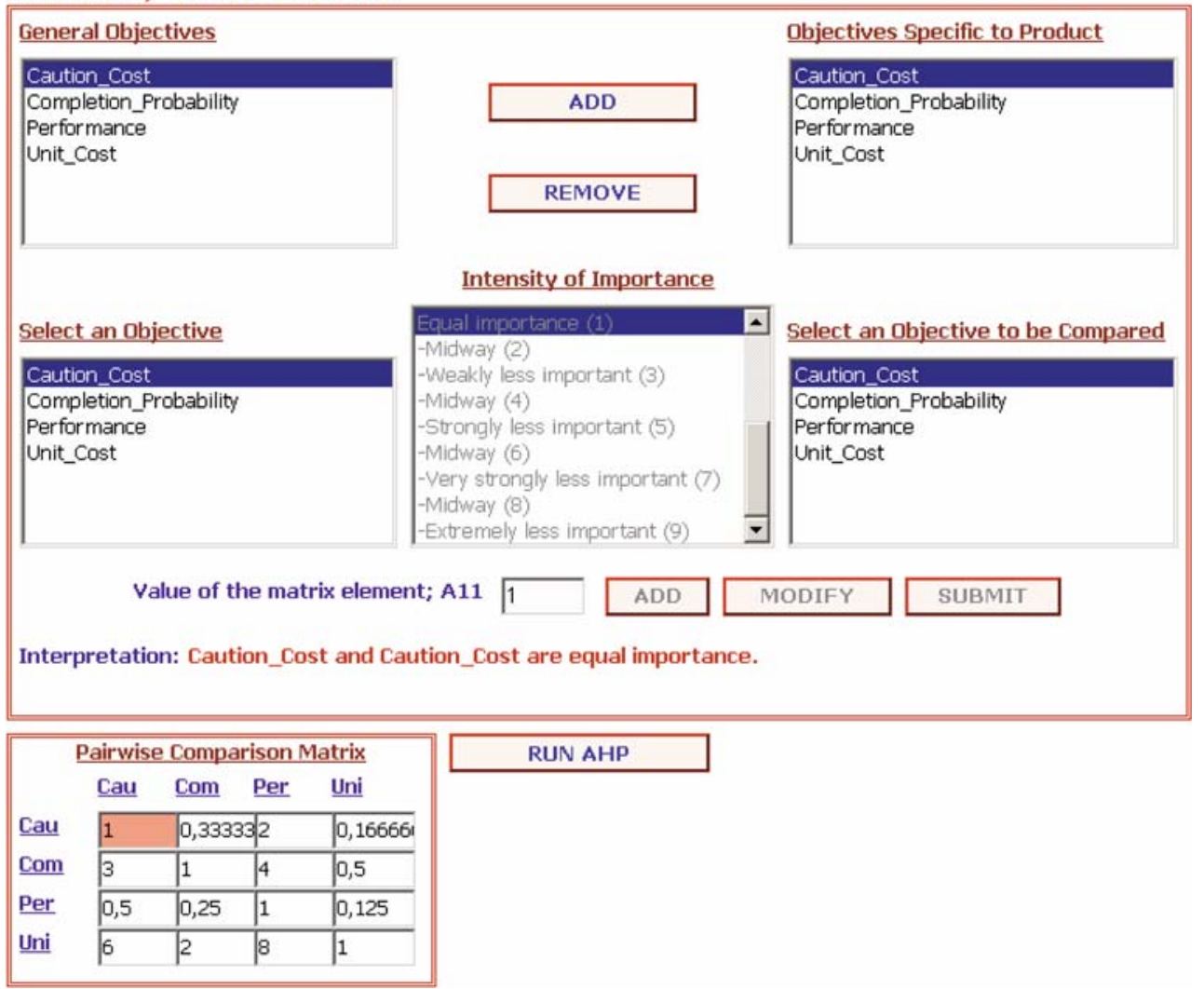

The AHP can be viewed by a community as a public consultation process that takes their views and aspirations into account, and generates expectations about management decisions. This can have a downside if tough decisions have to be made to arrest resource degradation. Anecdotal evidence suggests the decision-makers and other stakeholders are not automatically swayed by these kinds of methods; each stakeholder group may still insist on its preferred criteria and options. However, AHP does clarify the tradeoffs involved, and make the impacts of any particular course of action more transparent. In the case study, the AHP was linked with a generic multi-criteria analysis model, and provided a means of structuring the decision problem and estimating importance weights for the objectives of the various stakeholder groups.

A drawback sometimes arises with AHP known as 'rank reversal', which is associated with the relative nature of the judgements involved. Here, changing the set of alternatives changes the ranking of all alternatives. If new alternatives are likely to be added to the model after initial analysis, and alternatives are amenable to a direct rating approach (i.e., not so qualitative as to require pairwise comparison), then an approach in which ratings of alternatives are assigned directly (such as the simple multi-attribute rating technique or SMART) could be a better choice.
Fig. 4 Evaluation of the interested partners' scores

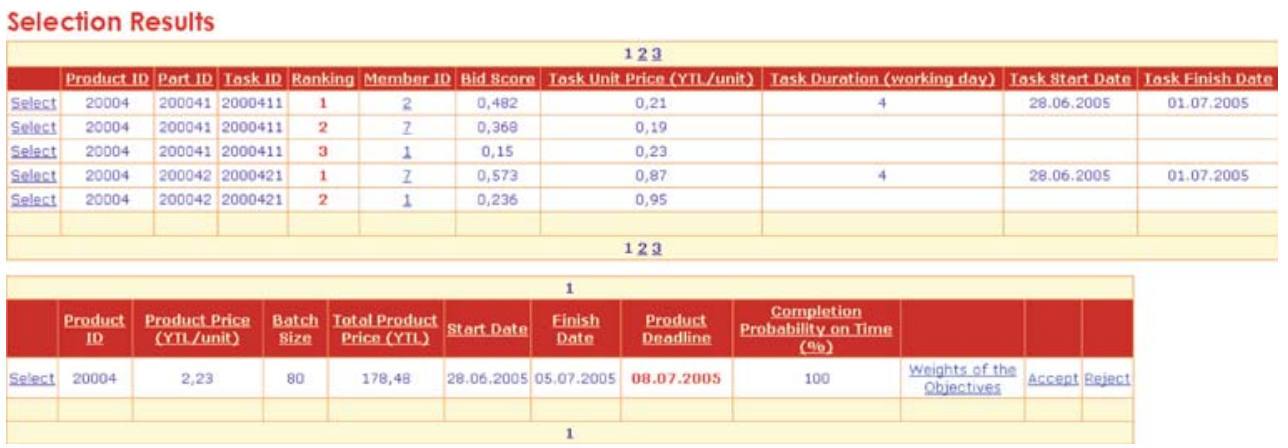


Acknowledgement We would like to express our gratefulness and appreciation to the Turkish State Planning Agency, Turkish Scientific and Technique Research Association and Graduate School of Natural and Applied Sciences of METU for their support throughout this research.

\section{References}

1. Sari B, Kilic SE (2004) Development of an SME-based Virtual Enterprise, Proceedings of the 11th International Machine Design and Production Conference, Antalya, Turkey, pp. 79-93, ISBN 975-429-227-2

2. Goranson, HT (1999) The agile virtual enterprise: cases, metrics, tools, Westport, CT: Quorum Books, ISBN 01567202640

3. Jagdev HS, Browne J (1998) The extended enterprise - a context for manufacturing. Prod Plan Control 9(3):216-245

4. Camarinha-Matos LM, Afsarmanesh H (1999) The virtual enterprise concept. In: Camarinha-Matos LM, Afsarmanesh $\mathrm{H}$ (eds) Pro- VE'99 book, Infrastructure for virtual enterprises: networking Industrial enterprise s. Kluwer Academic Publishers, Boston Dordrecht London, pp. 3-14

5. NIIIP (1996) The NIIIP reference architecture, http://www.niiip.org.

6. Barry J, Aparicio M, Durniak T, Herman P, Karuturi J, Woods C, Gilman C, Ramnath R (1998) NIIIP-SMART: An investigation of distributed object approaches to support MES development and deployment in a virtual enterprise. 2nd IEEE International Enterprise Distributed Computing Workshop

7. Afsarmanesh H, Garita C, Ugur Y, Frenkel A, Hertzberger LO (1999) Design of the federated information management architecture for PRODNET. In: Camarinha-Matos LM, Afsarmanesh $\mathrm{H}$ (eds) Pro-VE'99 book, Infrastructure for virtualenterprise s: networking industrial Enterprises. Kluwer Academic Publishers, Boston Dordrecht London, pp. 127-173

8. Zarli A, Poyet P (1999) A framework for distributed information management in the virtual enterprise: the VEGA project. In: Camarinha-Matos LM, Afsarmanesh H (eds) Pro-VE'99 book, Infrastructure for virtual enterprises: networking industrial enterprises. Kluwer Academic Publishers, Boston Dordrecht London, pp. 294-306

9. Wortmann JC (1992) Factory of the future: towards an integrated theory for one of a kind production. In: Hirsch BE, Thoben KD (eds) One of a kind production: new approaches. North-Holland, Amsterdam, pp. 37-74

10. Camarinha-Matos LM, Cardoso T (1999) Selection of partners for a virtual enterprise. In: Camarinha-Matos LM, Afsarmanesh $\mathrm{H}$ (eds) Pro-VE'99 book, infrastructure for virtual enterprises: networking industrial enterprise s. Kluwer Academic Publishers, Boston Dordrecht London, pp. 259-278

11. Gunasekaran A (1998) Agile manufacturing: enablers and an implementation framework. Int J Prod Res 36:1223-1270

12. Maloni MJ, Benton WC (1997) Supply chain partnership: opportunities for operations research. Eur J Oper Res 101: 419-448

13. Brucker P (1999) Resource-constrained project scheduling: notation, classification, models, and methods. Eur J Oper Res 112:3-41

14. Elmaghraby SE (1977) Activity networks-project planning and control by network models. Wiley, New York

15. Wang D, Yung KL, Ip WH (2001) A heuristic genetic algorithm for subcontractor selection in a global manufacturing environment. IEEE Trans Syst Man Cybern C 31(2):189-198

16. Wu NQ, Mao N, Qian YM (1999) An approach to partner selection in agile manufacturing. J Intell Manuf 10(6):519-548

17. Petroni A, Braglia M (2000) Vendor selection using principal component analysis. J Supply Chain Manag 36(2):63-69

18. Purdy L, Safayeni F (2000) Strategies for supplier selection: A framework for potential advantages and limitations. IEEE Trans Eng Manage 47(4):435-443

19. Sarkis J, Talluri S (2002) A model for strategic supplier selection. Trans Eng Manage 38(1):18-28

20. Haykin S (1994) Neural networks, a comprehensive foundation. Macmillan, New York

21. Saaty TL (1980) The analytic hierarchy process. McGraw-Hill, New York

22. Gray CF, Larson EW (2000) Project management - The managerial process. McGraw-Hill

23. Sari B, Kilic SE, Sen DT (2006) Formation of dynamic virtual enterprises and enterprise networks. International Journal of Advanced Manufacturing Technology, 2006, DOI 10.1007/s00170006-0688-y

24. Sari B, Amaitik S, Kilic SE (2006) A neural network model for the assessment of partners' performance in virtual enterprises. International Journal of Advanced Manufacturing Technology, DOI 10.1007/s00170-006-0642-Z 